\title{
Image analysis, impedance spectroscopy and mercury porosimetry characterisation of freeze-drying porous materials
}

\author{
S. Blacher 1,2, V. Maquet 2,3, R. Pirard 1, J.-P. Pirard 1, R. Jérôme 2,3 \\ 1 Department of Chemical Engineering, University of Liège, Sart-Tilman, B6 4000 Liège, Belgium \\ 2 Center for Research and Education on Macromolecules, University of Liege, Sart-Tilman, B6 4000 Liège, \\ Belgium \\ 3 Center of Biomaterials, University of Lie'ge, Sart-Tilman, B6, 4000 Liège, Belgium
}

\begin{abstract}
Image analysis and impedance spectroscopy have been used as potential tools for the characterization of the texture of ultramacroporous PLA foams prepared by freeze-drying. It has been shown that these two techniques actually provide valuable information on the structure of this material. They are complementary to mercury porosimetry, which does not allow morphological details to be distinguished. Image analysis of SEM micrographs of transverse cross-sections at two different magnifications gave information on both the macroporosity $(1 \mu \mathrm{m}<$ width $<10 \mu \mathrm{m})$ and ultramacroporosity (width $>10 \mu \mathrm{m}$ ). Impedance spectroscopy was used to investigate the transport properties of the three-dimensional porous matrices by measurement of ionic conduction.
\end{abstract}

Keywords: Polyactide foams; Image analysis; Impedance spectroscopy; Porous materials

\section{Introduction}

Porous biodegradable synthetic and natural polymers are currently tested as implants for the regeneration of damaged and diseased tissues [1-4]. One of the key features of tissue engineering is the scaffold porosity which ideally consists of a large population of pores. Pores larger than $10 \mu \mathrm{m}$ are essential for sustaining cell infiltration, whereas pores smaller than $10 \mu \mathrm{m}$ contribute to cell attachment and create a large surface area for the growth of tissue layer. The pore morphology is another key characteristic when the regeneration of highly organised tissues such as nerves, is concerned. Indeed, highly oriented porous scaffolds have a great potential as temporary implants for supporting axonal regeneration in the case of lesions of the rat sciatic nerve [5] and the spinal cord [6]. Recently, some of us reported on a thermally induced phase separation (TIPS) technique for the tailoring of macroporous biodegradable polylac-tide (PLA) supports and showed how the mechanism of polymer-solvent phase separation can lead to anisotropic or isotropic porous structure $[7,8]$. Important foam characteristics such as density, porosity and mechanical properties have been previously determined [7], and founded to be dependent on the processing conditions. However, a deeper characterisation of the macro- and ultra-macrostructure of this class of materials is desirable to understand better the interdependence of the TIPS process, the final properties of the freeze-dried matrices and their ability to support tissue repair. Traditionally, mercury porosimetry is used to measure the porous volume and the pore size distribution of porous matrices. Nevertheless, there is experimental evidence that these matrices are shrunk, i.e., compacted and not intruded by mercury. This behaviour has been already observed in other system presenting a high porosity $[9,10]$. In this study, the image analysis and impedance spectroscopy are discussed as non-destructive methods for the characterization of foams prepared by the solid-liquid phase separation of PLA solution in 1,4-dioxane. In this system, nu-cleation and growth of the crystallised solvent-rich phase and its subsequent sublimation result in an oriented network composed of ultramacrop-ores of $\approx 100 \mu \mathrm{m}$ diameter dispersed in a ten times less porous matrix (i.e., median pore size of $10 \mu \mathrm{m}$ ) [5]. The orientation of the ultramacropo-res is parallel to the cooling direction and depends on both the polymer concentration and polymer crystallinity. In this study, the structure and porosity of the freeze-dried foams are searched for in the case of amorphous poly(D,L-lactide) (DL-PLA) and semi-crystalline poly(L-lactide) (L-PLA) matrices at various polymer concentrations. Density and porous size distributions are determined by image analysis of two-dimensional transverse cross-sections of the matrices. The transport properties of the three-dimensional structures are assessed by the ionic conduction measured by the application of an alternative current to water-saturated polymer matrices. The relationships between data collected from these two techniques and the mechanical properties of PLA foams has been investigated elsewhere [11]. According to IUPAC, porous materials with $w>50 \mathrm{~nm}$ are referred to as macroporous. In this work, pores with width larger than the cell dimension $(\mathrm{w}>10 \mu \mathrm{m})$ will be designated as ultra-macropores and macropores will refer to pores smaller than $10 \mu \mathrm{m}$. 


\section{Materials and methods}

Poly D,L-lactide (DL-PLA), or Resomer ${ }^{\circledR}$ R206 (Mn: 50000) and poly L-lactide (L-PLA), or Resomer ${ }^{\circledR}$ L206 (Mn: 60 000, 70\% of crystallinity), were supplied by Boerhinger (Ingelheim, Germany). Polymer matrices were prepared by freeze-drying, as previously reported [5,6], from 1, 5, and $10 \mathrm{w}: \mathrm{v} \%$ polymer solution in 1,4-dioxane, so leading to the six foams listed in Table 1.

\subsection{Image analysis}

The foams were cut parallel to the surface and the transverse cross-sections were sputtered with platinum for 120 s under an argon atmosphere. Samples were observed with a Jeol JSM-840 A at an accelerating voltage of 20 $\mathrm{kV}$. SEM micro-graphs magnified 10 times and 100 times, respec-tively, allowed the ultramacropores $(\approx 100 \mu \mathrm{m}$ width) and the macropores ( $\approx 10 \mu \mathrm{m}$ width) to be discriminated properly, and they were analysed by image analysis. Image treatment and statistic analysis were performed with a Workstation Sun SPARC30, and the software 'Visilog5.0' from Noesis. Images were digitized on a matrix of $1024 \times 1024$ pixels with 256 gray levels. Five images of different areas of the same sample were analysed.

Table 1: Composition of the polymer foams

\begin{tabular}{lll}
\hline Foam name & Polymer type & Polymer concentration \\
\hline DL-PLA 1 & DL-PLA & $1 \mathrm{w}: \mathrm{v} \%$ \\
DL-PLA 5 & DL-PLA & $5 \mathrm{w}: \mathrm{v} \%$ \\
DL-PLA 10 & DL-PLA & $10 \mathrm{w}: \mathrm{v} \%$ \\
L-PLA 1 & L-PLA & $1 \mathrm{w}: \mathrm{v} \%$ \\
L-PLA 5 & L-PLA & $5 \mathrm{w}: \mathrm{v} \%$ \\
L-PLA 10 & L-PLA & $10 \mathrm{w}: \mathrm{v} \%$ \\
\hline
\end{tabular}
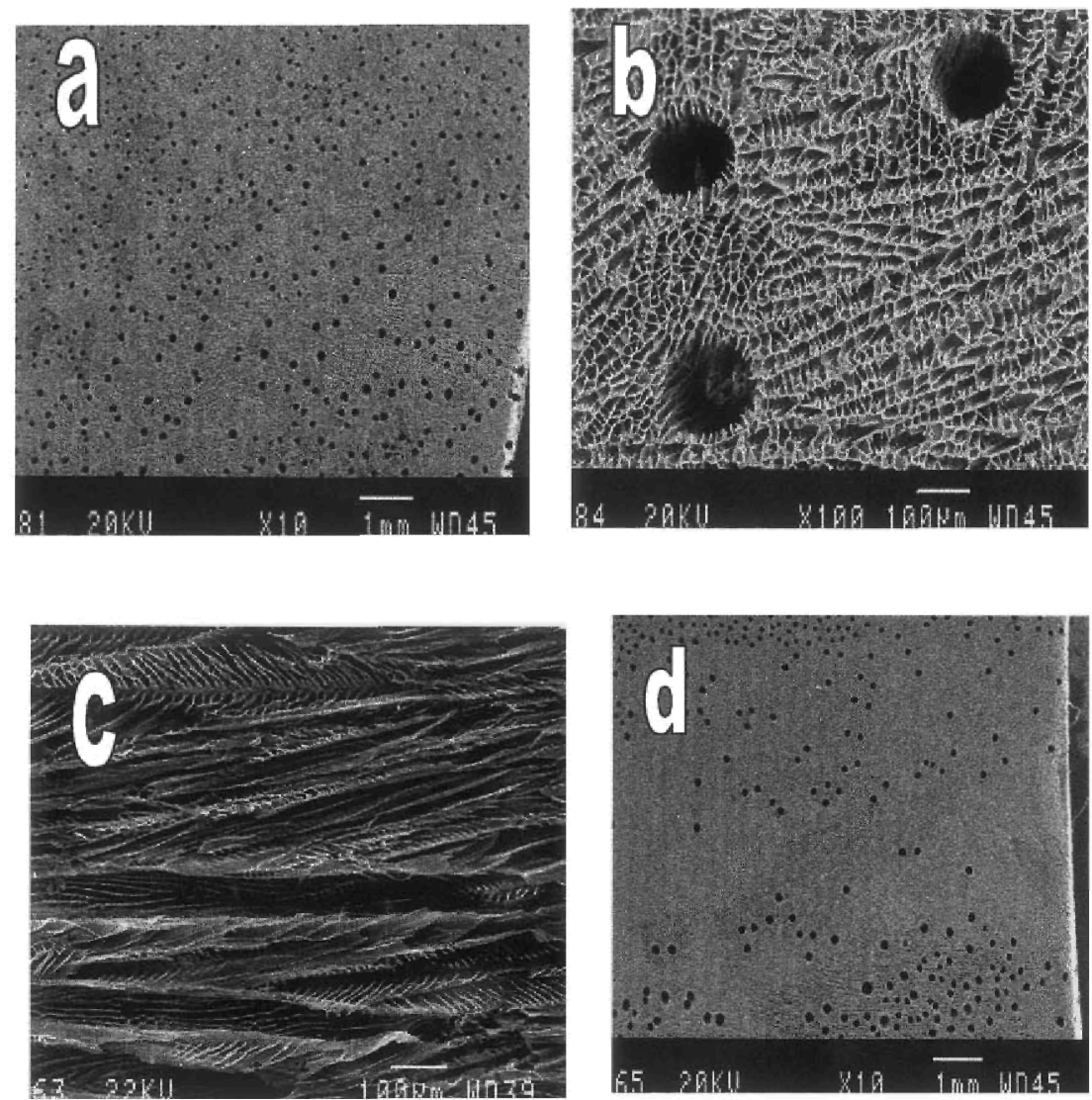

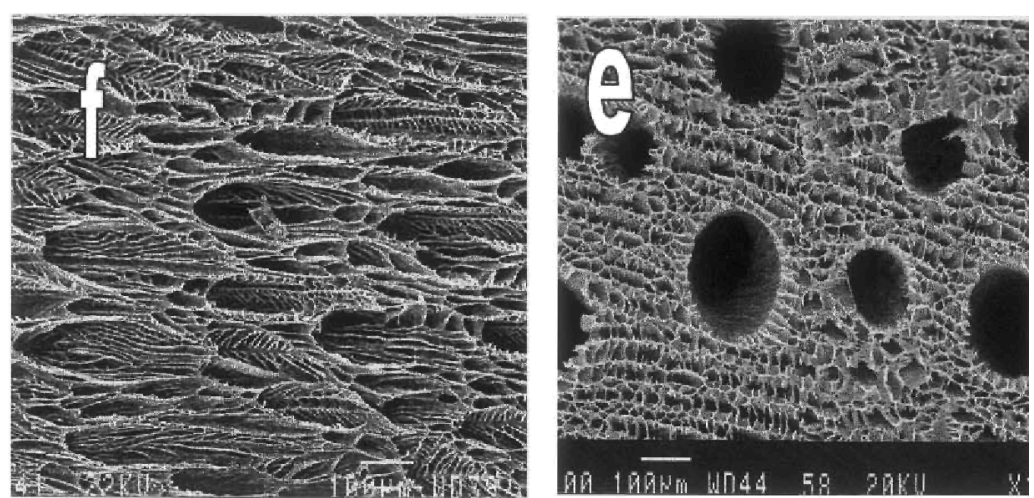

Fig. 1. Scanning electron micrograph of transverse $(a, b, d, e)$ and longitudinal $(c, f)$ cross-sections of L-PLA (a-c) and DL-PLA (d-f) foams at $\times 10(a, d)$ and $\times 100(b, c, e, f)$ magnification.

\subsection{Impedance spectroscopy}

One cubic centimetre specimen of each foam was degassed in distilled water and placed in an UV cell between two stainless steel electrodes. The cell was filled with distilled water and ionic AC electrical conductivity was measured by the Frequency Analyzer (Schlumberger) SI 1255 analyzer, supplied with the Chelsea Dielectric Interface (Model CDI 4t) probing the $10^{-3}-106 \mathrm{~Hz}$ frequency range.

\subsection{Mercury porosimetry}

Foams were previously dried overnight under reduced pressure of $10^{-5}$ Torr. The mercury porosimetry was performed using a porosimeter Carlo Erba 2000. The measurements were performed between 0.01 and $200 \mathrm{MPa}$. For data interpretation, a contact angle of $140^{\circ}$ and a surface tension of $0.48 \mathrm{Nm}^{-1}$ were used.

3. Results and discussion

Matrices obtained from PLA solution in 1,4-dioxane show two levels of porosity, i.e., ultra-macropores of $\approx 100$ $\mu \mathrm{m}$ width distributed in a macroporous matrix with pore size in the $10 \mu \mathrm{m}$ range. Fig. 1 shows typical transverse and longitudinal cross-sections of foams at various magnifications. This morphology is observed for both the LPLA and DL-PLA foams prepared from 5 and $10 \mathrm{w}: \mathrm{v} \%$ solutions. Conversely, no ultramacropo-rosity is observed for the foams prepared from dilute polymer solutions in dioxane (i.e., $1 \mathrm{w}: \mathrm{v} \%$ ), and the depth resolution is not good enough for reliable two-dimensional image analysis to be performed. 


\section{Image analysis characterisation}

Processing image binarization

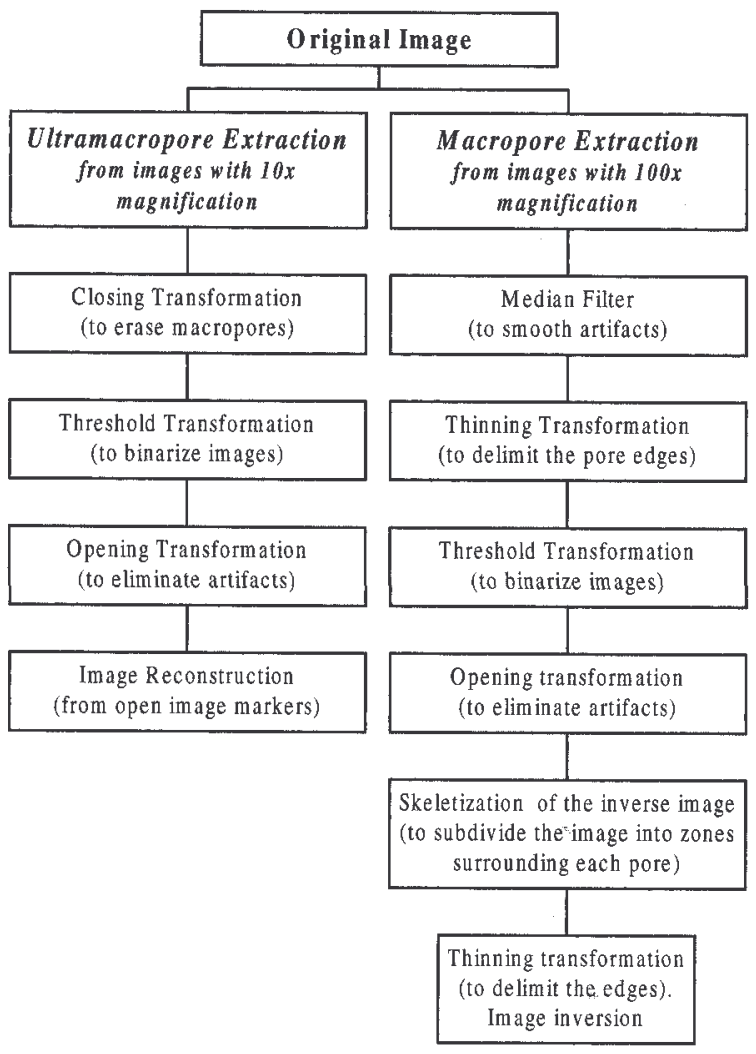

Fig. 2. Processing image binarization scheme to extract ultra-macropores and macropores. Procedure [12,13].

The quantitative analysis of transverse cross-sections requires to know both the density and size distribution of the ultramacropores and the density and size distribution of the macropores. Gray level image transformations and binary image processing are the preliminary steps of the Fig. 2 illustrates the steps followed to extract the macro and ultramacroporos-ity from the transverse cross-sections of PLA foams at 5 and $10 \mathrm{w}: \mathrm{v} \%$

concentrations. This procedure was not valuable for analysing longitu-dinal cross-sections that will be studied in forth-coming papers. It must also be noted that most of these transformations are parameter dependent. As a rule, if all the images are digitized under the same conditions, parameters are fixed once and for all, and the image binary processing is then completely automatic. In this study, the process-ing parameters have been changed for each set of images, because brightness and contrast were not the same. As an example, Fig. 3 shows two gray level images and the result of binary image processing.

From the images with a $10 \times$ magnification, three characteristic features have been calculated: the ultramacropore density $\left(\delta_{\mathrm{M}}\right)$, where $\delta_{\mathrm{M}}=$ Number of pixels that are characteristic of the ultramacropores/Number of pixels of the whole image, (b) the equivalent circular diameter of the ultramacropores $D=\sqrt{ }(4 A / \pi)$, where $A$ is the number of pixels for each pore multiplied by a calibration constant square and (c) the average distance between the ultramacropores $(\lambda)$.

From images recorded with a $100 \times$ magnifica-tion, four characteristic features have been calcu-lated: (a) the macropore density $\left(\delta_{\mathrm{m}}\right)$, where $\delta_{\mathrm{m}}$ is the number of pixels that are characteristic of the macropores/number of pixels of the whole image, (b) the circularity, $C$ is the perimeter ${ }^{2} / 4 \pi$ Area, which describes the deviation of an object from a true circle; a minimum value of 1 indicates a circle whereas larger values are indicative of shapes having a higher ratio of perimeter area, (c) be-cause of the irregular shape of the macropores, calculation of an equivalent circular diameter is irrelevant. Then, the macropore area distribution $(A)$ has been measured. The density $\left(\delta_{\mathrm{M}}\right)$ and the average diameter $(D)$ of the ultramacropores, the average distance be-tween the ultramacropores $(\lambda)$, the density $\left(\delta_{\mathrm{m}}\right)$, the average area $(A)$ and the average circularity $(\bar{C})$ of the macropores are reported in Table 2. For the sake of comparison, the total porosity as measured by mercury porosimetry is also reported in Table 2. Comparison of $\delta_{\mathrm{M}}$ and $\delta_{\mathrm{m}}$ shows that the macropores contribute to a large part of foam porosity. $\delta_{\mathrm{m}}$ is largely independent of the sample composition, whereas $\delta_{\mathrm{M}}$ decreases with the solution 
concentration (from 5 to $10 \mathrm{w}: \mathrm{v} \%$ ), whatever the PLA type.

$D$ and $\lambda$ increase with the solution concentration. At the same time, the average size of the macropores $(\bar{A})$ decreases while their shape remains almost unchanged $\left(\bar{C}_{\approx 1.4)}\right.$ whatever the polymer type and concentration. Finally, on the assumption that the two-dimensional porosity can be extrapolated to the three-dimension space, combination of $\delta \mathrm{M}$ and $\delta \mathrm{m}$ systematically leads to a total porosity smaller than that one measured by mercury porosimetry, although the general trend is the same.
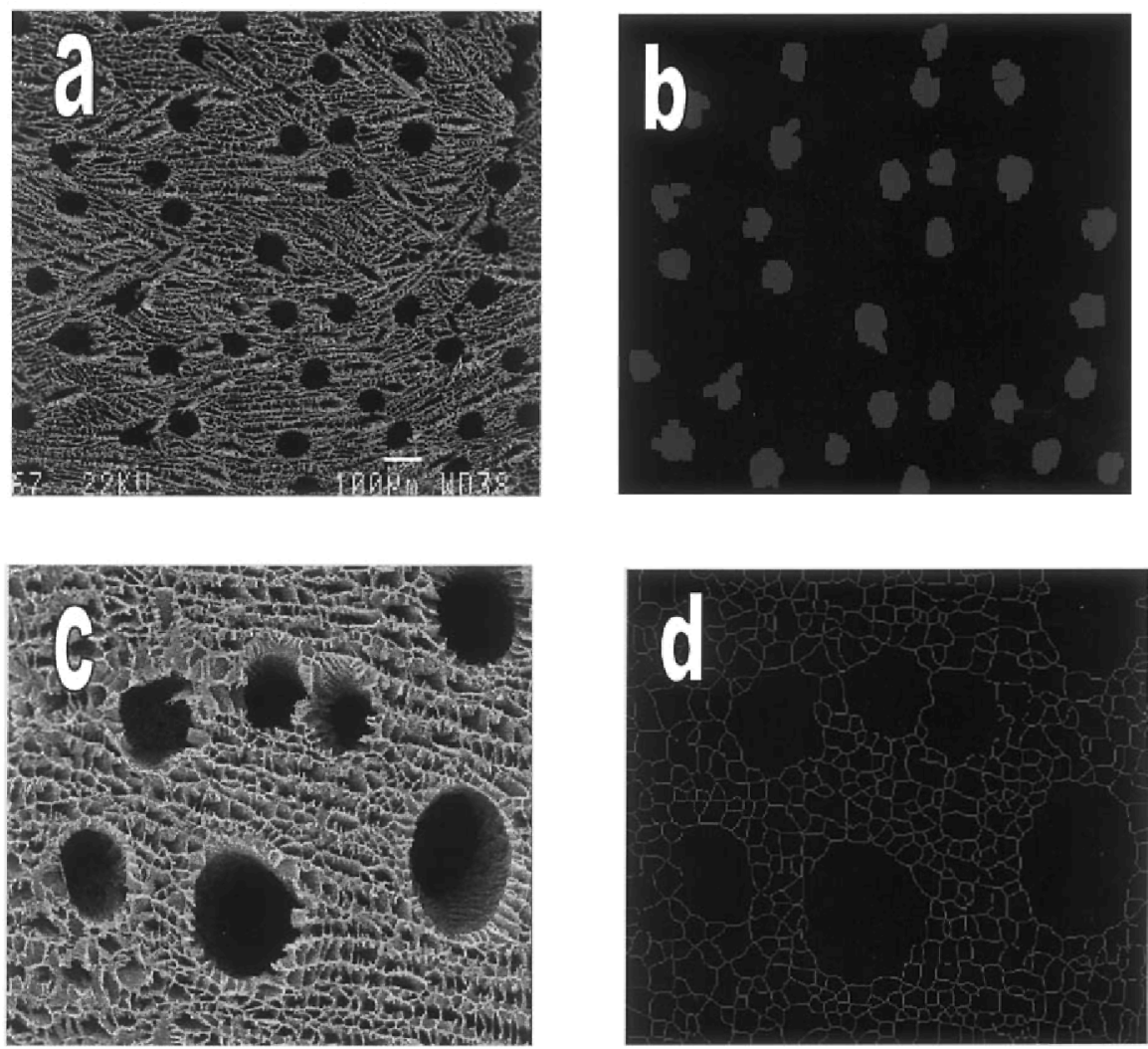

Fig. 3. Extraction of the ultramacropore $(a, b)$ and macropore $(c, d)$ structure from the L-PLA 10 foam.

\subsection{Dielectric properties}

It is well known that the conducting properties of a liquid in a porous medium provide information on the pore geometry and the pore surface area [14]. Indeed, both the motion of free carriers and the polarization of the pore interfaces contribute to the total conductivity. The main study in this field deals with the frequency dependence of conductivity for water or brine-saturated rocks [14] and porous glasses [15-17]. Let be $\varepsilon^{\prime}$ and $\sigma^{\prime}$ the dielectric constant and the conductivity, re-spectively. Dielectric properties are usually ex-pressed by the frequencydependent real and imaginary components of the complex dielectric permittivity:

$$
\varepsilon^{*}(\omega)=\varepsilon^{\prime}(\omega)-i \varepsilon^{\prime \prime}(\omega)=\varepsilon^{\prime}(\omega) \varepsilon_{0}-\frac{i \sigma^{\prime}(w)}{\omega},
$$

where $i=\sqrt{ }(-1), \varepsilon_{0}$ is the dielectric permittivity of the vacuum, fis the frequency in $\mathrm{Hz}$ and $\omega=$ $2 \pi f$. Experimental data are usually shown as a $\log$ - $\log$ plot of $\varepsilon^{\prime}$ and $\varepsilon^{\prime \prime}$ against frequency. Alternatively, $\varepsilon^{\prime}$ can be plotted against $\varepsilon^{\prime \prime}$, which is referred to as the Cole-Cole plot.

Freeze-dried matrices are three-dimensional solids consisting of an oriented (or not) (ultra) macropore network, through which ionic species can migrate depending on the network structure. Based on previous works on watersaturated rocks and glasses, we have tried to extract information about the three-dimensional structure of the freeze-dried matrices from the dielectric response. Fig. $4 \mathrm{a}$ and $\mathrm{b}$ shows the $\log \log$ plots for $\varepsilon^{\prime}, \varepsilon^{\prime \prime}$ and $\sigma^{\prime}$ as function of frequency of the dry foam and the distillated water used in our experiences. For the dry foam, $\varepsilon^{\prime \prime}$ (or $\left.\sigma^{\prime}\right)$ is negligible whereas $\varepsilon^{\prime}$ is constant $\left(\varepsilon^{\prime}=210-12 \mathrm{~F}\right)$. For the water, the data agree with a near-Debye response [17] with a maximum in $\mathrm{e}^{\prime \prime}$ at low frequency, which corresponds to the electrode polarization, and $\varepsilon^{\prime \prime} \propto_{\omega^{-1}}\left(\sigma^{\prime}=\right.$ cte) and $\varepsilon^{\prime} \propto \omega^{-2}$ for $1 \mathrm{~Hz}<\omega<10^{7} \mathrm{~Hz}$. The conductivity plateau size in-creases and its height decreases with increasing distance between electrodes. This behaviour is characteristic of ionic conduction.

Fig. 5 compares longitudinal and transverse direction responses for foams prepared from semi-crystalline L-PLA 
and amorphous DL-PLA at 1 and $10 \mathrm{w}: \mathrm{v} \%$ concentrations. For DL-PLA the dielectric response is independent of the sample orientation whatever the polymer concentration. On the contrary, for L-PLA the slope $\sigma^{\prime}$ vs. $w$ at low frequency depends on the sample orientation. This result indicates that L-PLA foams present a higher degree of orientation than DL-PLA counterpart. Fig. 6 shows plots of $\sigma^{\prime}$ and $\varepsilon^{\prime}$ as function of frequency for foams prepared from solutions at 1, 5 and $10 \mathrm{w}: \mathrm{v} \%$ concentrations, the electrodes being placed in the longitudinal direction. The a As measured by mercury porosimetry [1].

Table 2: Image analysis for DL-PLA and L-PLA foams

\begin{tabular}{|c|c|c|c|c|c|c|c|}
\hline Foam name & $\delta_{\mathrm{M}}$ & $\overline{\bar{D}}(\mathrm{~mm})$ & $\bar{\lambda}(\mathrm{mm})$ & $\delta_{\mathbf{m}}$ & $C$ & $\bar{A}\left(10^{-2} \mathrm{~mm}^{2}\right)$ & Porosity ${ }^{a}$ \\
\hline DL-PLA 1 & - & - & - & - & - & - & - \\
\hline DL-PLA 5 & 0.108 & $0.097+0.019$ & $0.26+0.21$ & 0.21 & $0.21+0.323$ & $0.066+0.067$ & 0.91 \\
\hline DL-PLA 10 & 0.064 & $0.116+0.039$ & $0.52+0.13$ & 0.70 & $1.363+0.269$ & $0.060+0.055$ & 0.77 \\
\hline L-PLA 1 & & & & & & & \\
\hline L-PLA 5 & 0.087 & $\overline{0} .108+0.023$ & $0.32+0.12$ & $\overline{0} .67$ & $\overline{1} .3721 \quad 0.254$ & $\overline{0} .092+0.081$ & $\overline{0} .89$ \\
\hline L-PLA 10 & 0.062 & $0.135+0.027$ & $0.80+0.25$ & 0.68 & $1.3532+0.258$ & $0.080+0.068$ & 0.84 \\
\hline
\end{tabular}

reference water response is added to compare free ionic conduction and ionic conduction within polymer foams.

For frequencies $\omega \leq 10-{ }^{1} \mathrm{~Hz}$, the dielectric response of free water and of water within DL-PLA foams are almost superimposed for all concentrations, i.e., $\sigma^{\prime} \propto \omega^{1}$ and. $\varepsilon^{\prime} \propto \omega^{2}$ At

higher frequencies, the size of the conductivity plateau decreases and it height increases with concentration of the polymer foams. This suggests that DL-PLA foams confine the motion of charge carriers and that the higher the DL-PLA solution concentration, the more confined this motion.

At high frequencies, the dielectric response of water in L-PLA foams follows the same trend with solution concentration than in DL-PLA foams.
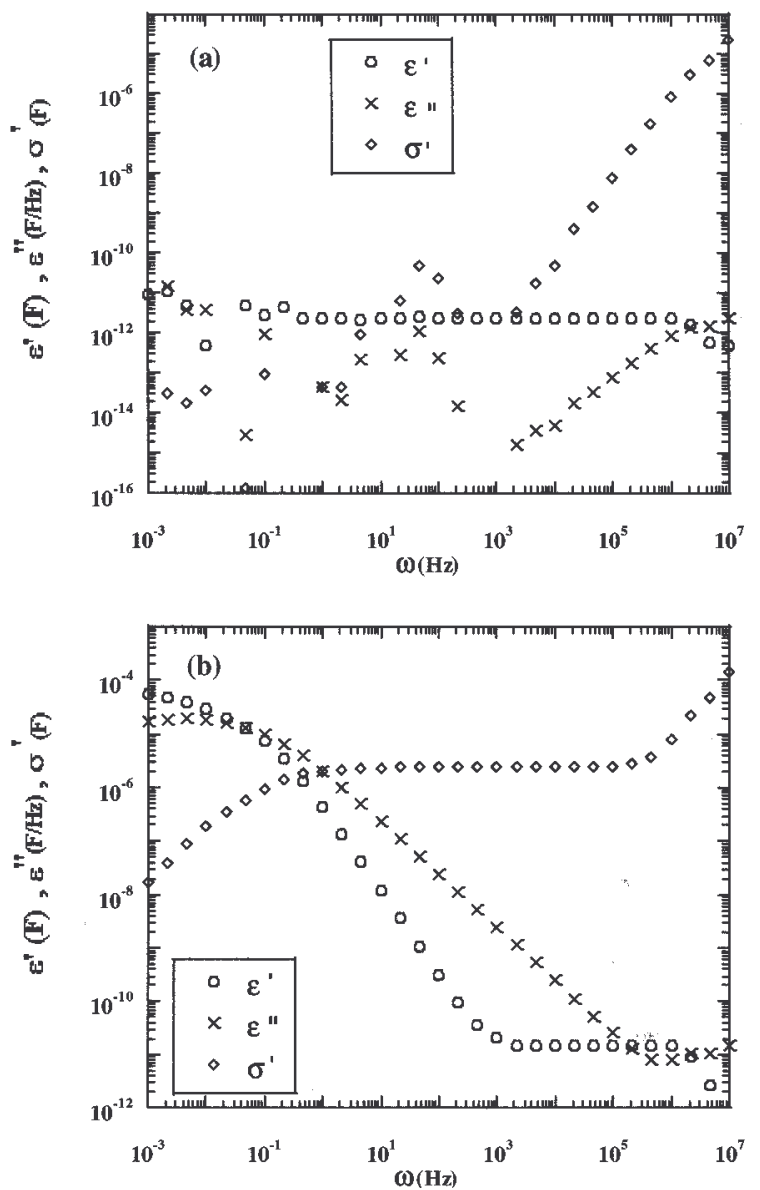

Fig. 4. Real $\left(\varepsilon^{\prime}\right)$ and imaginary $\left(\varepsilon^{\prime \prime}\right)$ components of the complex permittivity and conductivity $\left(\sigma^{\prime}\right)$ for the dry L-PLA10 foam (a) and the distillated water (b). 
Nevertheless, the increase in $\sigma^{\prime}$ and $\varepsilon^{\prime}$ values is less pronounced in case of L-PLA than DL-PLA foams. This behaviour indicates that the foam network does not hinder the charge carrier motion. For frequencies $\omega \leq 1 \theta^{-1}$ $\mathrm{Hz},{ }^{\prime} \propto w^{\mathrm{q}}$ with $q=1$ for the L-PLA 1 sample and $q<1$ when the concentration of the polymer solution increased. A slight increase in e' is also observed with the solution concentration in the same range. This dispersive behaviour indicates that when the L-PLA concentration is higher, the charge carriers move freely over more extended regions of the foams. This result leads to the conclusion that the network structure of L-PLA foams presents a higher degree of connectivity and is more sensitive to the polymer concentration than the DLPLA ones.

\section{Conclusion}

Porous polymer are promising materials for tissue engineering because they offer a temporary environment for cell seeding and subsequent transplantation into the host. The porosity and structure of these scaffolds are key characteristics for the success of this strategy. Mercury porosimetry is currently used to measure pore volume and pore size distribution of porous bio-materials. However, this technique is limited to pore size in the $7.5 \mathrm{~nm}-$ $75 \mu \mathrm{m}$ range, and shrinkage of the sample due to mercury penetration under high pressure can lead to incorrect pore size distribution. In this study, two novel methods were used to investigate the texture of porous PLA foams: image analysis and impedance spectroscopy. These two techniques have the advantage to be nondestructive for the pore structure and to allow information at different scales to be extract. The lower limit of image analysis is fixed by the quality of the SEM pictures. This limitation can explain the variations of porosity value as measured by image analysis and mercury porosimetry.

Image analysis shows that (a) the macropores contribute to a large extent to the foam porosity, (b) the size and morphology of macropores are independent of the foam composition (PLA na-ture and concentration), (c) the size of the ultra-macropores increases and their number decreases when the concentration of the polymer solution is increased, whatever the PLA type.
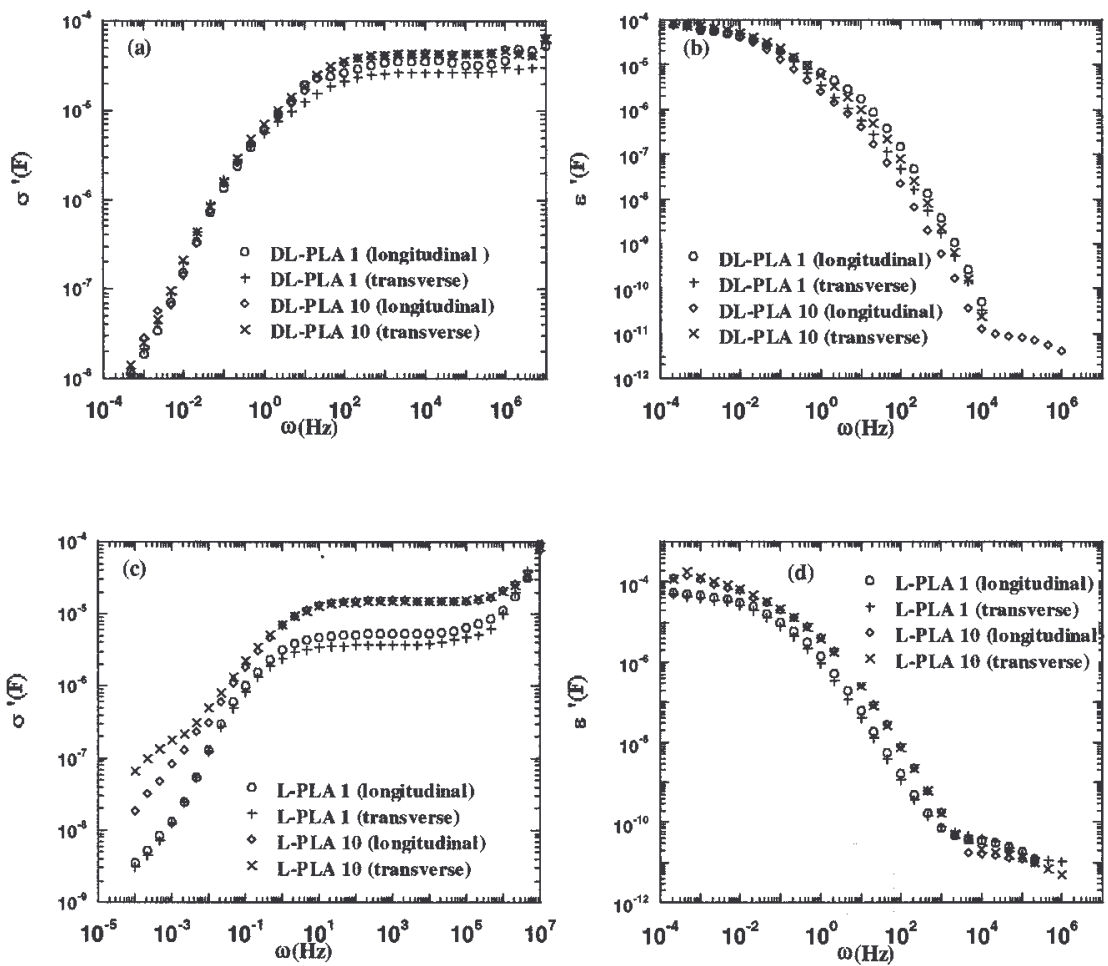

Fig. 5. Dielectric response of water in amorphous DL-PLA $(a, b)$ and in semi-crystalline L-PLA (c,d) foams, the electrodes being placed in the longitudinal and transverse directions.

Impedance spectroscopy measurements show that the dielec-tric response is sensitive to the particular structure of foams. Indeed, ionic conduction is easier through L-PLA foams compared to DL-PLA counterparts, this behaviour being more pro-nounced at high polymer concentration. These results lead to the conclusion that the network structure of L-PLA foams presents a higher de-gree of connectivity and is more sensitive to the polymer concentration than the DL-PLA counterpart.

As a conclusion, image analysis and impedance spectroscopy provide valuable information on the structure of a 
series of PLA foams prepared by freeze-drying. These two techniques are complementary to mercury porosimetry, which does not allow morphological details to be distinguished. To our knowledge, such a combination of charac-terisation techniques has never been reported be-fore and could be helpful for scientists active in the field of highly porous materials.

\section{Acknowledgements}

CERM is indebted to the Service Fédéraux des Affaires Scientifiques, Techniques et Culturelles (SSTC) in the frame of the 'Pôle d'Attraction Interuniversitaires: Chimie et Catalyse Supramoléculaire, and S. Blacher to the Conseil de la Recherche, Ulg, Belgium, for financial support. V.M. is 'collaborateur scientific', thanks to the Fonds National de la Recherche Scientifique (FNRS).
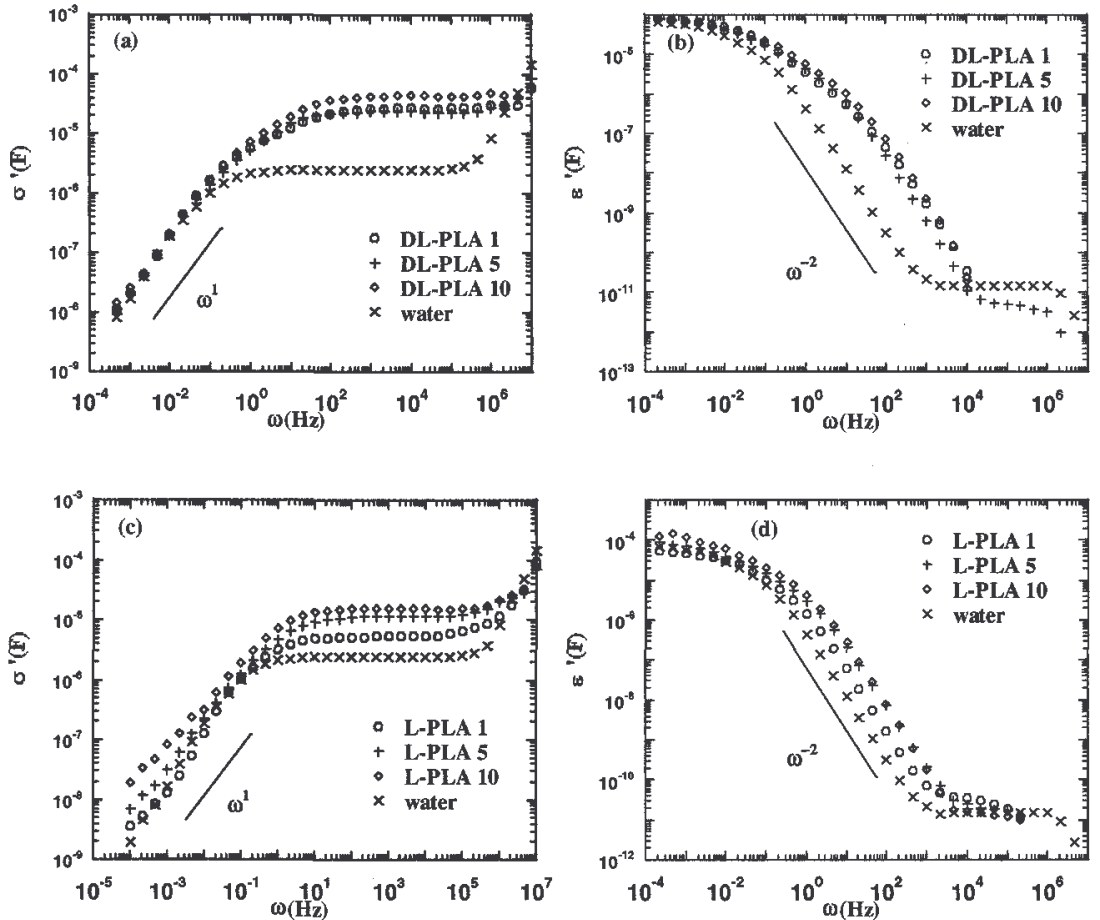

Fig. 6. Dielectric response for free water and for water in DL-PLA $(a, b)$ and L-PLA (c,d) foams prepared at different concentrations $(1,5$ and $10 \mathrm{w}: \mathrm{\%}$ ), the electrodes being placed in the longitudinal direction.

\section{References}

[1] C.W. Patrick, A.G. Mikos, L.V. McIntire (Eds.), Fron-tiers in Tissue Engineering, Pergamon Press, 1998. [2] R.P. Lanza, R. Langer, W.L. Chick (Eds.), Principles of Tissue Engineering, R.G. Landes Co. and Academic Press, Austin, 1997.

[3] M.S. Shoichet, J.A. Hubbel (Eds.), Polymers for Tissue Engineering, VSP: Utrecht, The Netherlands, 1998.

[4] V. Maquet, R. Jerome, In: Porous Materials for Tissue Engineering, vol. 250, Trans Tech Publications, Uetikon- Zuerich, 1997, pp. 15-42.

[5] V. Maquet, D. Martin, B. Malgrange, R. Franzen, J. Schoenen, G. Moonen, R. Jérôme, J. Biomed. Mater. Res, 52 (2000) 639.

[6] V. Maquet, D. Martin, F. Scholtes, R. Franzen, J. Schoenen, G. Moonen, R. Jerome, R. Biomaterials, in press.

[7] C. Schugens, V. Maquet, C. Grandfils, R. Jérôme, P. Teyssié, J. Biomed. Mater. Res. 30 (1996) 449.

[8] C. Schugens, V. Maquet, C. Grandfils, R. Jérôme, P. Teyssié, Polymer 37 (1996) 1027.

[9] R. Pirard, S. Blacher, F. Brouers, J.-P. Pirard, J. Mat. Res. 10 (1995) 2114.

[10] R. Pirard, S. Blacher, B. Sahouli, J.-P. Pirard, J. Colloid. Interf. Sci. 217 (1999) 216.

[11] V. Maquet, S. Blacher, R. Pirard, J.-P. Pirard, R. Jérôme, Langmuir, 16 (2000) 10463.

[12] J. Serra, Image analysis and mathematical morphology, New York, 1982.

[13] M. Coster, J.L. Chermant, Précis d'analyse d'images, CNRS, Paris, 1985.

[14] R Hilfer, R. Phys. Rev. B 44 (1991) 60.

[15] P. Pissis, A. Anagnostopolou-Konsta, L. Apekis, D. Daoukaki-Diamanti, C. Christodoulides, J. Non-cryst. Solids 131 (1991) 1174. 
Published in: Colloids and surfaces A: physicochemical and engineering aspects (2001), vol. 187-188, iss. 375-383 Status: Postprint (Author's version)

[16] P. Pissis, J. Laudat, D. Daoukaki, A. Kyritsis, J. Non- Cryst. Solids 171 (1994) 201.

[17] A. Gutina, E. Axelrod, A. Puzenko, A. Rysiakiewitz- Pasek, N. Kozlovich, Y. Feldman, J. Non-Cryst. Solids 235-237 (1998) 302 . 